\title{
Aproximación al estudio de las vistas urbanas de ciudades españolas en el teatro de Lope de Vega: las vistas de Valencia y Toledo*
}

\section{A First Approach to the Study of Urban Views of Spanish Cities in Lope de Vega: The Views of Valencia and Toledo}

\section{Eva Gutiérrez Prada}

UNED

ESPAÑA

evagutierrezprada@gmail.com.

[Hipogrifo, (issn: 2328-1308), 8.2, 2020, pp. 127-154]

Recibido: 18-12-2019 / Aceptado: 16-01-2020

DOI: http://dx.doi.org/10.13035/H.2020.08.02.09

Resumen. A través del análisis de la representación de la ciudad en algunas obras de Lope de Vega se pueden distinguir dos técnicas: la «representación metonímica» en la que un atributo o parte define toda la urbe, y las "vistas urbanas" en las que diferentes elementos de la ciudad restituyen un mapa mental de la misma. Mediante el estudio comparado de estas corografías lopescas con las historias de ciudades, crónicas y vistas urbanas hemos podido identificar características comunes que subyacen a una cultura visual que regía la contemplación y la representación la ciudad. La iconografía urbana en Lope es heredera de la tradición de las laudes civitatum, por un lado; y por otro, de la cartografía urbana con la que comparten el mismo punto de vista. Todo ello debe contextualizarse en la vocación de cronista que tuvo siempre Lope.

* Este trabajo fue presentado al IV Simposio Internacional sobre el teatro español como objeto de estudios «Representaciones de la ciudad en el teatro español: del Siglo de Oro a la actualidad» (Varsovia, 31 de mayo-1 de junio de 2019). Forma parte de un estudio más amplio que estamos concluyendo para el programa de doctorado en Historia, Historia del Arte y Territorio de la UNED. Por motivos de espacio hemos limitado aquí a dos ejemplos nuestra exposición. 
Palabras clave. Vistas urbanas; laudes civitatum; corografía; cronista; iconografía urbana; Lope de Vega.

Abstract. By analyzing the representation of the city in some of Lope de Vega's works, we could distinguish two techniques of urban representation: the metonymic's one, in which one part defines the whole city, and the views in which different elements bring back an urban mental map. The comparative study of these Lope's chorographies along with the chronicles, the stories of the cities, as well as the cartography, enables the identification of common elements within the same visual culture of the observation and representation of the city. Lope's urban iconography, first, goes back to the tradition of the laudes civitatum; and, then, to the urban cartography, with which it shares the same point of view. All this Lope's ambition of being a chronicler.

Keywords. City views; laudes civitatum; Corography; Chronicler; Urban iconography; Lope de Vega.

Nota, advierte y repara qué bien pinta, qué bien imita, con cuánto afecto y fuerza mueve su pintura las almas de los que le oyen?

Con estas palabras se refería Carducho a la habilidad con la que Lope de Vega representaba diferentes ambientes, época y personajes engañando a la vista y a los sentidos ${ }^{2}$. En esa recreación de la ciudad, los escritores del Siglo de Oro tenían «la misma idea de perfección urbana a la que intentan aproximarse las ciudades de la época con sus transformaciones», y la misma idea de ciudad de los tratados, vistas urbanas e historias de ciudades es «la que preside las alabanzas que estos escritores hacen de las ciudades» de la España Moderna. Aunque fueran géneros literarios tan distintos, los escritores se muestran «como si hubieran leído los tratados sobre arquitectura y ciudad del Renacimiento y del Barroco» ${ }^{3}$.

Lope de Vega vivió y escribió en un momento en el que el género corográfico -entendido en sentido amplio como cartografía, vistas urbanas e historias de ciudades o santos patronos, etc. ${ }^{4}$ - tuvo un fuerte desarrollo y en él confluían tanto las imágenes de ciudades como las laudes civitatum en un paralelo literario, «topoi de expresión de la magnificencia urbana» ${ }^{5}$. Tanto en las vistas como en las descripciones, la imagen de la ciudad aparecía asociada a un determinado momento de gloria, o vinculado al propósito celebrativo con el que había sido creado, difundiéndose las excelencias urbanas a través de una iconografía laudatoria que influyó en Lope de Vega y en su forma de contemplar la ciudad y de representarla. Cabría preguntarse, pues, qué tipo de lecturas u obras consultaba el poeta a la hora de

1. Carducho, Diálogos de la pintura, diálogo IV, pp. 147-148. Hemos adaptado en todos los casos la ortografía al uso moderno respetando las contracciones típicas de la época.

2. Sobre el engaño y el mundo de las apariencias barroco, ver Maravall, 1983, pp. 394 y ss.

3. Cámara Muñoz, 2008, p. 121.

4. Sobre el género corográfico ver Kagan, 1996.

5. Gómez López, 2016. 
documentarse y representar el espacio urbano ${ }^{6}$. Contamos en este sentido con algunos datos ciertos que la crítica ya ha puesto de relieve como su formación en la Academia de Matemáticas entre 1583 y 1586 con Juan Bautista Labaña y Pedro Ambrosio de Ondériz ${ }^{7}$, donde se reunían cosmógrafos, cronistas, arquitectos, ingenieros, pintores, etc. También frecuentó en Sevilla entre 1602 y 1604 el ambiente intelectual en torno a la figura de Juan de Arguijo y Francisco Pacheco, con quien sin duda se debatían cuestiones sobre pintura 8 . En Toledo mantuvo relaciones con los intelectuales de la Academia del Conde de Fuensalida9', a la que pertenecía El Greco o Francisco de Pisa, personajes sobre los que volveremos más adelante. Por lo que se refiere a la biblioteca personal de Lope de Vega, de los «mil quinientos libros» ${ }^{10}$ con los que contaba no conocemos ningún título, pero podemos hacer una reconstrucción hipotética a través de los autores que el propio Lope cita en sus obras y también revisando los títulos y autores que configuraban las bibliotecas de otros intelectuales de la época ${ }^{11}$. Las obras de Estrabón, Cicerón, Platón, Plinio, Pomponio Mela, Tito Livio, Ptolomeo, Apiano y Ortelio, además de las historias de ciudades de escritores modernos ${ }^{12}$ - que remitían a estos clásicos - eran frecuentes en las bibliotecas privadas de los intelectuales del Siglo de $\mathrm{Oro}^{13}$. Así que podemos suponer que Lope, si no tuvo ejemplares de estas obras, sí las conocía y las utilizaba como inspiración en sus comedias ${ }^{14}$ y pudo consultarlas directamente en las bibliotecas de sus mecenas, como el Duque de Alba, o a través de polianteas y diccionarios como Ravisuis Textor o Carolus Stephanus ${ }^{15}$. También pudo tener conocimiento indirecto de ellas a través de las citas de escritores modernos como Luis Cabrera de Córdoba, Gil González Dávila o Jerónimo de la Quintana ${ }^{16}$, a los que

6. Subrayamos aquí que Lope destacó en el género corográfico con obras como el Isidro o el poema sobre la Virgen de la Almudena, ver sobre el tema Sánchez Jiménez, 2012.

7. El propio autor en el proceso de Elena Osorio dice haber estudiado matemáticas y astronomía en la Academia Real, ver Zamora Vicente, 1961; Arellano Ayuso y Mata, 2011, pp. 58-59; Esteban Piñeiro, 2002, p. 15. Sobre la Academia de Matemáticas ver García Barreno, 1995, pp. 9-185 y 2006, pp. 135-195; Romo Santos, 2016.

8. Ver Portús Pérez, 1999, p. 139

9. Cfr. Blecua, 1961, pp. 459-462. El nombre de Lope no figura en la lista de humanistas pertenecientes a la Academia y, además, Lope no llega a Toledo hasta 1604. Para esas fechas el conde de Fuensalida ya se había trasladado a la corte, pero Lope tuvo relación con el grupo de literatos y artistas cercanos a la Academia, cfr. Madroñal Durán, 2012.

10. Inventario de los bienes de Lope fechado el 5 de febrero de 1627, publicado en Davis, 2004, pp. 160-171.

11. Sobre la "hipotética" biblioteca de Francisco de Quevedo, El Greco o Velázquez ver la base de datos IBSO. Sobre estos dos últimos artistas, ver también Riello, 2014 y Sánchez Cantón, 1925, respectivamente.

12. Sobre el género de historias de ciudades hispanas, ver Quesada, 1992.

13. Sobre la difusión de estos libros de historias de la ciudad, con 500 tiradas, ver Kagan, 1996, p. 91.

14. De Calderón, por ejemplo, nos dice Devos que, no habiendo estado en Granada, pudo utilizar este tipo de materiales como fuente de localización para la obra El Tuzaní de las Alpujarras (ver Devos, 2007, p. 86). Podemos pensar, por tanto, que este tipo de documentos sirviera a los escritores en el proceso creativo de sus obras.

15. Ver Sánchez Jiménez, 2010.

16. Estos autores aparecen en el listado de 2007 ofrecido por la RAE para la reconstrucción del estudio de la Casa Museo de Lope de Vega en Madrid en el que colaboró la Biblioteca Nacional con 400 libros impresos entre los siglos XVI y XVII hasta 1635. Agradezco a la Casa Museo los datos facilitados. 
podemos añadir autores como Marineo Sículo, Pedro de Medina, Pérez de Mesa o Francisco de Pisa ${ }^{17}$.

Por lo que se refiere a las vistas de ciudades que tanto desarrollo tuvieron entre los siglos XVI y XVII en España podemos suponer que conociera el atlas de ciudades más importante y difundido de la época, el Civitates Orbis Terrarum de Braun y Hoefnagel (1572-1617) ${ }^{18}$. Además de los grabados, Lope contempló la galería de ciudades del Palacio de El Viso, aunque ésta no contara con vistas de ciudades españolas ${ }^{19}$. Sí pudo deleitarse en la observación de vistas de ciudades españolas de gran formato, hoy perdidas, que Wyngaerde realizara para decorar las paredes del Alcázar de Madrid, El Pardo, y también Valsaín 20 . Posteriormente, algunas de ellas fueron trasladadas al Escorial entre 1571 y $1611^{21}$. En concreto en la Sala Grande, futuro Salón de Comedias del Alcázar, Lope pudo haber contemplado las vistas de Sevilla, Toledo, Valencia o Zaragoza 22 . No se sabe con exactitud cuáles eran las normas de acceso a las residencias reales pero, según Portús Pérez, si personas "de opinión" tenían acceso, Lope de Vega pudo visitar no solo las partes públicas de los palacios, sino también los salones y galerías privados ${ }^{23}$. Que conocía al maestro flamenco lo demuestra la onomástica de La discordia en los casados (161124), comedia en la que uno de los personajes es Antón de las Viñas - Antonio de las Viñas como se le llamaba al flamenco en España-, alemán y villano ${ }^{25}$, que supone en nuestra opinión un simple guiño al artista.

Las vistas de ciudades se realizaban también sobre otro tipo de soportes como tapices, estampas, grabados, muebles, libros o maquetas, alcanzando una amplia difusión. En La prisión sin culpa (1599-1603) ${ }^{26}$ uno de los personajes regala «un Toledito pequeño / con que te huelgues acá» 27 , lo que hace suponer que estos mo-

\footnotetext{
17. Sobre los intelectuales de Toledo y la Academia de Fuensalida ver Blecua, 1961.

18. Braun y Hogenberg, 1965 .

19. Sobre esta galería ver Del Campo Muñoz, 2004 y López Torrijos, 2009 y 2016.

20. Ver Galera i Monegal, 1998, pp. 70-77; Haverkamp Begemann, 1986, p. 63; Kagan, 1986, p. 11 y 2009 , pp. 98 y 106 y ss. Ver también Cámara Muñoz y Gómez López, 2011, pp. 146-147. Los estudiosos, en función de las descripciones de Argote de Molina y Diego Cuelbis, atribuyen a Wyngaerde esa colección de vistas perdidas en los incendios del Pardo en 1604, El Escorial en 1673 y el Alcázar en 1734, ver Galera i Monegal, 1998, p. 31.

21. Galera i Monegal, 1998, p. 71. Sobre el programa decorativo de tipo cartográfico y científico del Escorial, ver Checa Cremades, 1992, pp. 380 y ss

22. Para la decoración de estas salas, ver Checa Cermades, 1994, pp. 142-147.

23. Portús Pérez, 1999, p. 116. Su teatro da muestras de un conocimiento de los mejores lienzos del Alcázar. Visitó también el Escorial hacia 1600 como el propio poeta afirma en La tragedia del rey don Sebastián e indica Portús Pérez. Al Escorial dedica una comedia donde ofrece una detallada descripción y menciona también algunos pintores como Tiziano, Rubens y Navarrete, ver Lope de Vega, La octava maravilla, acto I, sobre todo vv. 66 y ss. y vv. 240-247. Según Valdés, Lope siguió la descripción del Padre Sigüenza (ver Valdés, 2001). Esto demuestra el tipo de proceso de documentación previo a la redacción de las comedias.

24. Presotto, 2000, p. 89

25. Antón es un nombre de villano frecuente en las comedias de Lope, Morley y Tyler, 1961, vol. I, pp. 21 y 44. 26. Morley y Bruerton, 1968, p. 50.

27. Lope de Vega, La prisión sin culpa, acto I, fol. $141 \mathrm{v}$.
} 
delos, o las tareceas o tablas pintadas de tema urbano, entraron a formar parte de la cultura de prestigio de las élites también en España ${ }^{28}$.

Conocida es, por otro lado, su afición a la pintura y las relaciones que mantuvo con diferentes artistas, así que no resulta extraño el amplio conocimiento sobre cuestiones pictóricas demostrado en sus obras ${ }^{29}$. En ámbito cartográfico y corográfico, hemos rastreado en Lope algunas referencias a instrumentos utilizados por agrimensores, cartógrafos y topógrafos para realizar mediciones como el astrolabio ${ }^{30}$ o la ballestilla o báculo de Jacob ${ }^{31}$ y, sobre todo, el cuadrante para la técnica de triangulación, instrumentos todos ellos que formaban parte de las bibliotecas de aristócratas y eruditos. Lope pudo haber visto y haber utilizado este tipo de instrumentos en la Academia de Matemáticas que primero estuvo en el Alcázar hasta $1628^{32}$. Plantea también debates relacionados con la perspectiva y técnica de la pintura en las representaciones de ciudades, aspecto que describe muy bien, por ejemplo, en El Castigo del discreto (1598-160133):

$\begin{array}{ll}\text { CASANDRA } & \text { No has visto cuando un pintor } \\ & \text { forma una ciudad en lejos? [...] } \\ & \text { en que esta pintura } \\ & \text { del lienzo [...] } \\ & \text { la vista entre niebla oscura. } \\ & \text { Aquel estar yo mirando } \\ & \text { si es ciudad o no es ciudad [...] } \\ & \text { [...] de sus pinturas } \\ & \text { de sus cercas, y sus lejos [...] } \\ & \text { Yo creo que al acercarse, } \\ & \text { lo que ciudad parecía } \\ & \text { vendrá por ventura hallarse } \\ & \text { una sombra en que podría } \\ & \text { el alma desengañarse }{ }^{34} .\end{array}$

28. De la difusión de mapas, paisajes y vistas como objetos decorativos en las casas holandesas dan prueba las obras de Vermeer, ver Alpers, 1987. Acerca del uso, sobre todo bélico, de las maquetas en ámbito hispánico, ver Cámara Muñoz, 2016.

29. Para la relación de Lope de Vega con los pintores y su interés y preocupación sobre temas relacionados con la pintura, ver Portús Pérez, 1999 y Sánchez Jiménez, 2011.

30. Menciona este instrumento en la Isagoge a los Reales, en La Vega del Parnaso, III, 2015, pp. 221-222. El diccionario de Autoridades ejemplifica la definición de astrolabio con una cita de La Circe de Lope, cit. en La Vega del Parnaso, III, 2015, p. 22. También lo cita en Porfiando vence amor, 1637, acto II, fol. 118r. 31. Mencionado en Lope de Vega, Soliloquios amorosos de un alma a Dios, soliloquio VII.

32. Para las distintas ubicaciones de la Academia de Matemáticas, ver Soraluce Blond, 1987. Carducho nos ofrece una descripción de cómo estaba decorada la Academia en Diálogos de la pintura: «sobre espaciosas mesas se veían globos, esferas, cuerpos regulares, y otros instrumentos matemáticos y geométricos», cit. en Pereda, 2002, p. 36. Por el inventario de bienes sabemos que, además de libros e instrumentos, había también mapas. Sobre el coleccionismo de Felipe II en materia de astronomía y cartografía, tanto en el Alcázar como en el Escorial, y la decoración cartográfica, ver Checa Cremades, 1992 y Santiago Páez, 1994.

33. Morley y Bruerton, 1968, p. 301.

34. Lope de Vega, El castigo del discreto, acto I, vV. 193-217. 
Lope plantea aquí cuestiones como la perspectiva, no tanto como regla matemática de representación de la realidad, sino como «orden de apariencias visuales» 35 para el espectador. Por otro lado, el engaño ${ }^{36}$ del que habla Lope ante ese estilo abocetado ${ }^{37}$ demuestra un gusto por la contemplación de las vistas urbanas y conocimientos de pintura. No solo hace alarde de estar al día sobre los debates pictóricos en boga en la época, sino también sobre cuestiones técnicas. Por ejemplo, en Los ramilletes de Madrid (161538) refiriéndose a la pintura o perspectiva que «suele hacer los "lejos"» menciona indirectamente la técnica de la cámara oscura, en la que «ciudad altiva / se ve en pequeños espejos» "39. Este instrumento permitía dibujar la imagen urbana proyectada en el interior de una caja mediante un sistema de lente y espejo ${ }^{40}$. Esta técnica conocida desde la Edad Media ${ }^{47}$, se empieza a emplear sistemáticamente a partir de la segunda mitad del siglo XVI y, sobre todo, en el XVII con el avance de la lente biconvexa de Jean Baptista Porta. Fueron muy utilizadas en el siglo XVII por los holandeses ${ }^{42}$.

Todos estos datos sobre los conocimientos e intereses pictóricos del poeta nos conducen directamente al tema que queremos afrontar, es decir, la manera en la que Lope representa la ciudad a través de los parlamentos de sus personajes en algunas obras que, sin pretensión de exhaustividad, nos parecen representativos. Así pues, entre las técnicas lopescas de representación de la ciudad nosotros distinguimos dos: la «representación metonímica» y las vistas urbanas.

La «representación metonímica» de la ciudad es un proceso simbólico en el que «un artefacto concreto, un edificio o plaza particular [...] pasa a convertirse en metáfora [o icono] de toda la ciudad a través de un proceso de cabría definir como representación metonímica» ${ }^{43}$. De la misma manera que en las vistas corográficas o en las historias de ciudades se resaltaban ciertas zonas de la ciudad o ciertos lugares emblemáticos, el teatro se apropia también de esta concretización de toda la ciudad en un lugar o aspecto específico, en una parte metafórica de la ciudad, una cualidad, una excelencia, un monumento, un personaje ilustre, que representa la ciudad toda y es símbolo de grandeza y nobleza urbana. La victoria del Marqués

35. Panofsky, 1973, pp. 55-56, cit. en Maravall, 1983, p. 401.

36. Sobre el concepto de apariencia, realidad, engaño y desengaño en la cultura del Barroco, ver Maravall, 1983, pp. 398-418.

37. Sobre la "técnica de lo inacabado", ver Maravall, 1983, pp. 421 y ss. En cuanto al estilo abocetado en pintura y literatura ver Portús Pérez, 1999, p. 31.

38. Morley y Bruerton, 1968, p. 93.

39. Lope de Vega, Los ramilletes de Madrid, acto III, fol. $71 \mathrm{v}$.

40. Sobre el uso de lentes y cámaras y la pintura de paisajes en ámbito holandés ver Alpers, 1987, sobre todo pp. 66 y 93. Los términos espejos, ante nuestro ojos o lentes se habían aplicado a mapas y pinturas de la época, Alpers, 1987, p. 223.

41. Es una técnica conocida desde que el árabe Alhazen (965-1039) observara el fenómeno de la cámara oscura en su tratado de óptica. El tratado fue traducido al latín en Toledo en el siglo XII y a partir de ahí se difundió por Europa. Se le ha atribuido a este autor la invención de la cámara oscura, pero parece que sería anterior, cfr. Pedersen, 1993 y Kircher, Ars Magna, Lucis et Umbrae, p. 34.

42. Sobre el tema ver Alpers, 1987, p. 46 y 88.

43. Kagan, 1998a, p. 47. Tomamos el término de este autor. 
de Santa Cruz, escrita en $1604^{44}$ cuando la corte estaba todavía en Valladolid, abre su segundo acto con un desembarco en Nápoles ${ }^{45}$, una de las ciudades más importantes, bellas y prósperas de la época:

\begin{tabular}{ll} 
CARPIO & Esta es Nápoles. \\
ROSELA & \multicolumn{1}{c}{ Es bella. } \\
CARPIO & Qué vista, qué majestad. \\
ROSELA & ¿Habrá en España ciudad \\
& que se compare con ella? \\
CARPIO & Granada tiene hermosura, \\
& imperio y valor Toledo, \\
& Valladolid lustre, Oviedo \\
& fortaleza, Cuenca altura, \\
& Lisboa tiene riqueza, \\
& Ávila armas, Salamanca \\
& letras, Antequera es franca; \\
& Segovia trato y limpieza, \\
& León tiene antigüedad, \\
& Toro y Zamora abundancia, \\
& Soria haber sido Numancia, \\
& Zaragoza majestad, \\
& fuerza y soldados Pamplona, \\
& campos Trujillo, y Plasencia \\
& nobleza, y galas Valencia, \\
& gran tesoro Barcelona, \\
& Córdoba caballería, \\
& altos blasones Baeza, \\
& las dos Jereces nobleza, \\
& mary y defensa Almería, \\
& y por no te cansar más, \\
& con referir más ciudades, \\
ni de sus antigüedades, \\
decir lo que ya sabrás, \\
sola Sevilla iguala, \\
en comercio, trato y gente. \\
Brava máquina46. \\
& \multicolumn{1}{c}{ Excelente. }
\end{tabular}

44. Morley y Bruerton, 1968, p. 593.

45. Hasta donde se sabe, Lope no estuvo en Nápoles, pero tuvo la "experiencia visual" de la ciudad a través de la galería de ciudades de El Viso como ya hemos señalado. Sobre la comedia de Lope y la exaltación política y militar del personaje histórico contemporáneo, ver Ferrer Valls, 2012. Sobre las comedias de ambientación napolitana y la relación y significado con los diferentes géneros, ver Piqueras Flores y Santos de la Morena, 2019.

46. Sobre el término máquina o fábrica para referirse a una ciudad, ver Covarrubias, Tesoro de la lengua castellana o española, fol. 102r. 


\begin{tabular}{ll} 
ROSELA & $\begin{array}{l}\text { Altas grandezas señala. } \\
\text { Deseo ver el cuartel } \\
\text { de los españoles. }\end{array}$ \\
CARPIO & \multicolumn{1}{c}{ Tiene } \\
& la grandeza que conviene \\
a los que viven en él ${ }^{47}$.
\end{tabular}

Entre las cualidades hispanas que destaca tenemos, por ejemplo, la gloriosa historia goda de Toledo, Civitas Regia y ciudad Imperial; Valladolid era ilustre porque residía allí la corte ${ }^{48}$, y Cuenca por la altura del sitio, Salamanca por la universidad; de Valencia destaca la nobleza ${ }^{49}$, pero la belleza y majestad de Nápoles - con esa doble naturaleza española y extranjera50 - solo se puede igualar a Sevilla «bellísima por su riqueza, grandeza y majestad, trato, policía, puerto y puerta de Indias» ${ }^{51}$. Otros ejemplos aparecen en El amante agradecido (160252), El Arenal de Sevilla $\left(1603^{53}\right.$ ) y en La burgalesa de Lerma $\left(1613^{54}\right)$ donde Lope ofrece una galería de maravillas de diferentes ciudades españolas, codificando un catálogo de excelencias urbanas como exaltación, tanto de lo local, como de las posesiones del Imperio de la monarquía hispánica que se concretizaban en el espacio urbano.

La segunda técnica de representación son las vistas urbanas ${ }^{55}$ denominadas así porque es el término que utiliza el poeta, como hemos visto en los versos anteriores ${ }^{56}$. La ciudad es "vista", "contemplada", conocida a través de la observación y

47. Lope de Vega, La nueva victoria del marqués de Santa Cruz, jornada II, fols. 198-199.

48. Afirmaba Botero que «las ciudades de más autoridad son aquellas, en las cuales los reyes antiguos tuvieron su Corte, Barcelona, Zaragoza, Valencia, Córdoba, Toledo, Burgos, León [...]» (Diez libros de la razón de Estado, lib. II, fol. 222v).

49. En otra comedia Lope menciona los «mil nobles caballeros» que vivían en Valencia, símbolo de la nobleza de la ciudad - El Grao de Valencia, acto II, vv. 2778-2784, pp. 513-546- que suponían el doble de los que menciona Müntzer: «viven condes, barones, algunos duques, más de quinientos caballeros ricos y otras personas de condición» (cit. en Boira Maiques, 1992, p. 60. De esta obra ver sobre todo el capítulo 3 sobre la imagen de la ciudad de Valencia y las fuentes literarias).

50. Ver Piqueras Flores y Santos de la Morena, 2019, p. 105.

51. Ver Lope de Vega, El peregrino en su patria, libro IV, fol. 167v.

52. Morley y Bruerton, 1968, pp. 48 y 80. Por motivos de espacio remitimos al lector a las obras, ver Lope de Vega, El amante agradecido, acto I, vv. 113-122, pp.100-140.

53. Ver Lope de Vega, El Arenal de Sevilla, acto I, vv. 401-420. Morley y Bruerton, 1968, p. 84.

54. Ver Lope de Vega, La burgalesa de Lerma, acto II, vv.1765-1779. Morley y Bruerton, 1968, p. 90.

55. Adoptamos del ámbito de la iconografía urbana la definición de vista porque es la que mejor se adapta a estos fragmentos literarios. Para las cuestiones todavía abiertas sobre clasificación y terminología, ver Skelton, 1965; De Seta, 1996, pp. 17-36 y 1999; Marías, 2002, p. 107; Kagan, 1998b. Sobre el mismo tema y el concepto de retrato de ciudad, ver Nuti, 1996, 2010 y 2017.

56. En las obras de Lope hay más ejemplos. He aquí algunos: en referencia a las ciudades españolas «Yo la doy por vista ya. / Haz cuenta que a Zaragoza, / que justamente se goza / por la grandeza en que está; / a la pintada Valencia, / a la Toledo Imperial» (El abanillo, acto I, vv. 578-583). En relación a la vista del Alcázar de Toledo al alejarse de la ciudad, afirma que es «grande y hermosa vista» (El alcaide de Madrid, jornada I, v. 8). En otra comedia exclama uno de los personajes: «iGran vista!» tienen las huertas del Prado, entrada que «ha de dar lustre y grandeza por esta parte a Madrid» (De cuándo acá nos vino, jornada III, vv. 2546-2547). O también en El desconfiado: «Apacible vista tiene Madrid» (El desconfiado, acto III, 
después "pintada"57. Además, comparten con los retratos de ciudades, en cualquiera de los soportes, la misma técnica de representación y el mismo objetivo: Lope "pinta" la ciudad con «un efecto totalizador, que devuelva una impresión de conjunto a la multiplicidad y diversificación de los elementos espaciales y genéricos» ${ }^{58}$, como defiende Oleza según las tesis de Wölffin. Así el poeta nos ofrece, en consonancia con los artistas de la época, una ciudad en perspectiva destacando las cualidades del sitio, la forma de la ciudad con sus murallas, torres y puertas, los puentes y, dentro del caserío, los edificios nobles y religiosos más importantes; y también algunos iconos de la modernidad como eran las calles anchas y rectas o las plazas espaciosas. El autor se aproxima, en su poética laudatoria de ciudades, a este género corográfico urbano en el que imagen y palabra van de la mano, representando verbalmente la ciudad en la que se situaba la acción, o una ciudad que uno de los personajes describe, formando parte de ese "decorado verbal"59 del espacio dramático ${ }^{60}$ que Lope recrea para la imaginación de los espectadores.

Como anunciábamos en el título, y por motivos de espacio, presentamos aquí las reflexiones sobre dos vistas urbanas de Valencia y de Toledo porque fueron, por un lado, dos ciudades en las que residió el poeta y conoció bien ${ }^{61}$, y además son los casos más representativos que hemos registrado de este tipo de técnica.

En Los locos de Valencia (1590-159562) la panorámica de la ciudad63 es la siguiente:

$$
\begin{aligned}
& \text { LEÓN } \quad \begin{array}{l}
\text { Esta, Erifila, es Valencia, } \\
\text { la puerta es esta de Cuarte; } \\
\text { aquí dio Venus y Marte } \\
\text { una divina influencia. } \\
\text { Estos son sus altos muros, } \\
\text { y aqueste el Turia, que al mar }
\end{array}
\end{aligned}
$$

vv. 2195-2196). De nuevo en El casamiento de la muerte cuando en la entrada triunfal del rey Alfonso en León dice: «Dad una vista a la ciudad famosa» (El casamiento de la muerte, jornada III, v. 2186). Con respecto a Valencia afirma que «a ser a mis ojos viene / la mejor que he visto, en fin. / Es de linda vista el mar, / y tan cerca de sus muros» (El bobo del colegio, acto I, vv. 651-654).

57. En la comedia La burgalesa de Lerma, en uno de los parlamentos que podemos considerar también una vista urbana de la villa «fundada a la vista de Burgos», Lope se expresa así: «si tuviera la destreza / que tuvo pintando Apeles, la villa y campo os pintara» (La burgalesa de Lerma, acto III, vv. 2411-2412 y acto II, vv. 1305-1307 respectivamente). Para el traspaso semántico de los términos 'pintar' y 'describir' en la época ver Portús Pérez, 1999, p. 40.

58. Oleza, 2013, p. 230.

59. Díez Borque, 1975, pp. 86-91.

60. Sobre la diferencia entre espacio escénico y espacio dramático, ver Díez Borque, 2002 -sobre todo el capítulo 3-y Vitse, 1996, p. 338 respectivamente.

61. En 1589 se marcha el poeta a Valencia para cumplir destierro de Castilla por libelos contra Elena Osorio. Permanecerá allí hasta 1590 momento en el que se marcha a Toledo, ver Arellano Ayuso y Mata, 2011, pp. 72 y ss.

62. Morley y Bruerton, 1968, p. 56.

63. No es la única vista que hemos registrado de la ciudad en Lope. Por motivos de espacio, remitimos al lector a El bobo del colegio, acto I, vv. 646-662. Otras descripciones más parciales aparecen en El Grao de Valencia. 


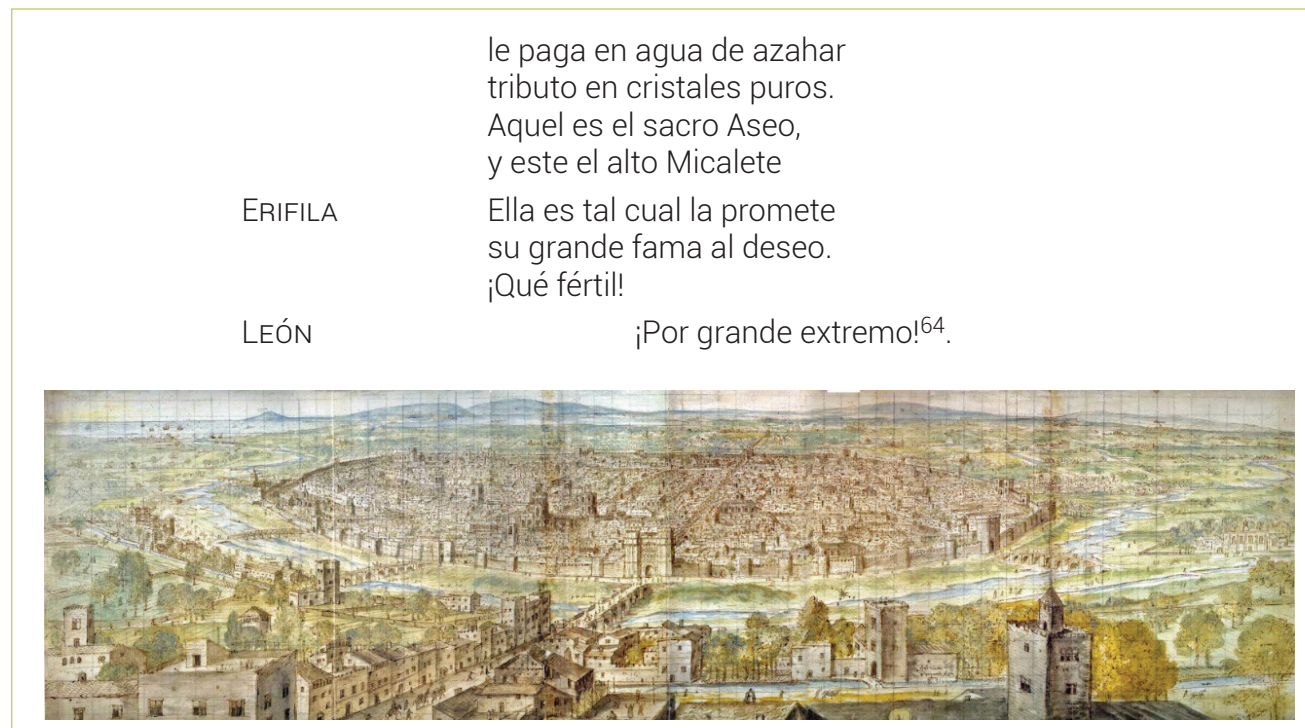

Fig. 1. Vista de la ciudad de Valencia (1563) de Anton van der Wyngaerde (Biblioteca Nacional de Viena)

Lope nos ofrece aquí una vista urbana bastante amplia con algunas excelencias como la puerta de Quart y la muralla, el río y el mar, la catedral y el Micalet o el Hospital General. Según Oleza, en estos versos el espacio es intangible, «es una cantidad elástica de extensión que se reduce o ensancha según la altura del vuelo de la imaginación» ${ }^{65}$ porque desde ningún punto de Valencia se puede tener esa vista. Bien es cierto, que la perspectiva de la catedral con el Micalet en primer término correspondería a un punto focal desde occidente, como podría ser la Puerta de Torrent, pero en ese caso no se comprendería la vista del río y la Puerta de Quart. Sin embargo, esta perspectiva bien puede coincidir con las vistas de Valencia que se fueron codificando desde el mismo punto focal que eligió Beuter para su vista icónica ${ }^{66}$ o Wyngaerde con una vista aparentemente más fidedigna (1563) ${ }^{67}$ (fig. 1), o más tarde Manceli en su plano (Nobilis ac Regia Civitas Valentie in Hispania, 1608)68: el punto desde el que se observa la ciudad y que se convertiría en la imagen oficial de la urbe es la fachada norte desde el camino Real de Zarago-

64. Lope de Vega, Los locos de Valencia, acto I, vv.131-144. Fue escrita tras su estancia en Valencia, entre 1590 y 1595, Morley y Bruerton, 1968, p. 56.

65. Oleza, 2013, pp. 207-208

66. Sobre las vistas icónicas y la clasificación de tipologías ver Marías, 1996, pp. 11-113 y 2002, pp. 104106. Sobre las vistas de Beuter, ver Cisneros Álvarez, 2012, pp. 139-157.

67. Sobre esta vista de Wyngaerde (Biblioteca Nacional de Austria) que Lope pudo contemplar en el Alcázar, ver Kagan, 1986, pp. 205-207; Aldana Fernández, 1987 y Roselló, 1990, pp. 104-105. Realizó también estudios previos conservados en el Victoria \& Albert Museum de Londres, entre los que nos interesa destacar dos: un estudio panorámico centrado en la muralla y los puentes con la puerta de Quart - signatura (95-H-54) 8455-5r- y un dibujo de menor tamaño con la muralla, la Puerta Nueva y la de Quart - signatura (95-H-54) 8455-22 (v)-, ver Galera i Monegal, 1998, pp. 130 y 145 respectivamente. 68. Ver Cisneros Álvarez, 2012, pp. 311-447 y Ramírez Aledón, 2017. 
za, con el río en primer plano. Es precisamente por ese lado por donde llegan los personajes a la ciudad en la comedia. Pero para dominar una vista de Valencia como la que nos presenta Lope es necesario adoptar un punto de vista más elevado, como en las vistas a vuelo de pájaro ${ }^{69}$. Por otro lado, y en consonancia con el género corográfico, Lope selecciona como elementos definidores de la ciudad las excelencias del sitio como el río Turia, símbolo de abundancia ${ }^{70}$, con sus cinco puentes que «no se sabe cosa igual en otra de las mayores del mundo. Arrimado [...] a cualquier destas, goza de una imagen del paraíso» ${ }^{71}$. Menciona también los altos muros como símbolo de defensa, orden y policía urbana ${ }^{72}$, pues es «bella ciudad, / de notable majestad / y hermosamente cercada» ${ }^{73}$. Lope incluye en concreto la Puerta de Quart - una de las doce puertas con las que contaba la ciudad ${ }^{74}$ como la Jerusalén celeste- que «en fortaleza y lindeza ocupa el segundo lugar después de la de Serranos» ${ }^{75}$. Las influencias planetarias también eran muy recurrentes en las historias de ciudades ${ }^{76}$, y en Valencia Venus y Marte procuran «dulzura [...] en la condición y trato: y el ser por otro cabo animosos y coléricos» ${ }^{77}$. Se nos presenta así una imagen ideal de Valencia como paraíso terrenal, «parece toda una jardín»78 con flores y abundancia de agua ${ }^{79}$; una ciudad rica en el trato y los negocios, símbolo económico del florecimiento del comercio del Mediterráneo en el siglo XV. Es precisamente en ese momento cuando se forja la imagen de Valencia como «Roma segunda» 80 que «de cuanto quiere abunda» con «edificios, seda y oro / y mil nobles caballeros» ${ }^{81}$ siendo «apacible su gente», «en extremo amorosa» ${ }^{82}$. Por último, menciona los símbolos de la ciudad caritativa con el Hospital General y también la

69. Para la definición di veduta a volo d'uccello, ver De Seta, 1996, p. 17 y 1999.

70. Sobre la elección del sitio fértil y abundante de aguas había teorizado Vitruvio, De Architectura, libro I, cap. IV; y posteriormente también Alberti, Los diez libros de arquitectura, libro IV, pp. 15-20.

71. Escolano, Década primera de la Historia de la insigne y coronada ciudad y Reino de Valencia, libro IV, cap. XI, p. 767.

72. Sobre la ciudad y las murallas ver De Seta y Le Goff, 1991.

73. Lope de Vega, El bobo del colegio, acto I, vv. 646-648.

74. Cfr. Escolano, Década primera de la Historia de la insigne y coronada ciudad y Reino de Valencia, libro IV, cap. XI, pp. 762 y ss.

75. Escolano, Década primera de la Historia de la insigne y coronada ciudad y Reino de Valencia, libro IV, cap. XI, p. 766.

76. Ver Quesada, 1992, pp. 91-92.

77. Escolano, Década primera de la Historia de la insigne y coronada ciudad y Reino de Valencia, libro I, cap. XXII, p. 190.

78. Lope de Vega, El bobo del colegio, acto I, v. 650.

79. El topos aparece ya en los cronistas árabes Al Sumaysir y Al Garnati y después los recoge también Müntzer, ver Boira Maiques, 1992, p. 58.

80. Lope de Vega, El Grao de Valencia, acto II, vv. 2778-2784, pp. 513-546. Estos versos de Lope son reflejo del debate entre los cronistas sobre si Roma es el primer nombre que recibe la ciudad de Valencia, o Valencia el nombre que recibe Roma - cfr. Escolano, Década primera de la Historia de la insigne y coronada ciudad y Reino de Valencia, libro IV, cap. IX, pp. 733 y ss.-, argumento en defensa de la antigüedad de la ciudad.

81. Lope de Vega, El Grao de Valencia, acto II, vv. 2778-2784, pp. 513-546.

82. Lope de Vega, El bobo del colegio, acto I, v. 667 y 662 respectivamente. 
ciudad devota ${ }^{83}$ con el Micalet de la Catedral. El Hospital de Pobres Inocentes, Hospital General a partir de $1512^{84}$ - o en palabras de Lope ««Sacro Aseo» en referencia al baño como medio higiénico y terapéutico para la limpieza y salud corporal85- fue pionero en Europa y entró a formar parte de las excelencias de la ciudad ${ }^{86}$ en un momento de auge de las políticas relacionadas con la policía urbana ${ }^{87}$. Tan grande fama debía tener el hospital que viajeros extranjeros iban a visitarlo88, pues «nadie viene aquí que no la vea [la casa de los locos]»89. Por último, Lope destaca entre los perfiles de la ciudad la torre campanario de Micalet que era una de las cosas de admiración del templo90. Era una torre de estilo gótico, en origen exenta, que se había unido a la iglesia a finales del siglo XV y «llamaronla Miguel el día de su baptismo» ${ }^{91}$. Lope nos ofrece la imagen ideal de una Valencia bella, noble, antigua, rica y abundante, misericordiosa, bien defendida ${ }^{92}$ en consonancia con el dibujo de Wyngaerde ${ }^{93}$; anclaba así la imagen de la urbe al periodo de mayor esplendor del siglo XV, Siglo de Oro valenciano, como hicieran también los cronistas Alonso de Proaza, el flamenco Lalaing, Enrique Cock o Escolano, resaltando «la modernidad, con toda su excelencia, el mundo gótico cristiano de los siglos XIV y XV ${ }^{94}$.

El segundo ejemplo de vista urbana que queremos comentar es el de Toledo que aparece en la segunda jornada de la comedia del Rey Bamba:

RODULFO Esta es la Vega famosa

del Tajo la plaza llana

y aquesta de Galiana

83. Sobre la ciudad caritativa y la ciudad devota en las historias de ciudades, ver Quesada, 1992, pp. 42-45. 84. Sobre la historia del Hospital de Pobres Inocentes ver Gómez-Ferrer Lozano, 1995.

85. Gómez-Ferrer Lozano, 1995, pp. 32-33. El tratamiento psiquiátrico no nace hasta el siglo XVIII, por lo tanto con este establecimiento de caridad, como se deduce del sermón del padre Jofre -que impulsó la fundación- «no se aspiraba a más que a subvenir a las necesidades corporales de los dementes y protegerlos contra las inclemencias del tiempo y contra las injurias de los hombres; a limpiar además, con más o menos esmero, a los sucios; cohibir a la fuerza a los furiosos, y atender a todos, según las doctrinas médicas de la época, en las enfermedades intercurrentes y en los accidentes que pudieran sobrevenirles» (Rodrigo Pertegás, 1927, p. 586).

86. Cfr. Escolano, Década primera de la Historia de la insigne y coronada ciudad y Reino de Valencia, libro V, cap. XXI, pp. 1047-1048.

87. De finales del siglo XVI y principios del XVII son las teorías de Vives y Pérez de Herrera.

88. García Mercadal, 1999, vol. I, p. 343.

89. Lope de Vega, Los locos de Valencia, acto II, v. 1539. Ver Zaragoza Rubira, 1964a, p. 414 y 1964b; López Terrada, 1986 y Vilar Devis, 1990. Todos estos historiadores afirman que Lope conoció el hospital, como él mismo demuestra en El peregrino en su patria, 1605. Para un análisis de las coincidencias entre el funcionamiento del hospital en la realidad y en la obra de Lope, ver Tropé, 1994, pp. 372-382.

90. Escolano, Década primera de la Historia de la insigne y coronada ciudad y Reino de Valencia, libro IV, cap. I, p. 894.

91. Escolano, Década primera de la Historia de la insigne y coronada ciudad y Reino de Valencia, libro IV, cap. I, p. 894

92. Nos referimos a las referencias de la torre de la atalaya en el Grao (El Grao de Valencia, jornada III, vv. 2053-2055). Sobre la fortificación en tiempos de Felipe II, ver Cámara Muñoz, 2005.

93. Ver Kagan, 1986, p. 194.

94. Marías, 2000, p. 28. 


\begin{tabular}{|c|c|}
\hline & $\begin{array}{l}\text { la morada deleitosa. } \\
\text { Mira la frescura y huerta } \\
\text { y mira mil maravillas. }\end{array}$ \\
\hline AtAÚLFo & $\begin{array}{l}\text { Aquestas son las Vistillas } \\
\text { y esta del Cambrón la puerta. }\end{array}$ \\
\hline ERVIGIO & $\begin{array}{l}\text { La puente de San Martín } \\
\text { es esta. }\end{array}$ \\
\hline BAMBA & $\begin{array}{l}\text { Como esta entera, } \\
\text { si es de tal santo creyera } \\
\text { della un peligroso fin. } \\
\text { Tengo señores gran miedo } \\
\text { que si le van a pedir } \\
\text { por Dios que le ha de partir } \\
\text { y hacelle falta a Toledo. } \\
\text { Santo por amor de Dios } \\
\text { que la puente nos dejéis, } \\
\text { mas como la dejaréis } \\
\text { si media capa dais vos. }\end{array}$ \\
\hline ATANAGILDO & $\begin{array}{l}\text { El Castillo San Cervantes } \\
\text { es este por do a la Sagra } \\
\text { se va, y esta es de Bisagra } \\
\text { la puerta de los gigantes. }\end{array}$ \\
\hline ATAÚLFO & $\begin{array}{l}\text { Este de labor mosaico } \\
\text { es el alcázar nombrado. }\end{array}$ \\
\hline BAMBA & $\begin{array}{l}\text { No es bueno, porque aun pintado } \\
\text { aborrezco lo judaico. }\end{array}$ \\
\hline TEÓFILO & $\begin{array}{l}\text { Esta es de Zocodover } \\
\text { la plaza y esta, señor, } \\
\text { llaman la plaza mayor. }\end{array}$ \\
\hline RODULFO & $\begin{array}{l}\text { Agora que resta de ver } \\
\text { la iglesia95. }\end{array}$ \\
\hline
\end{tabular}

Si tenemos en cuenta el punto focal desde el que se realiza la descripción lopesca debemos suponer que es fruto de la contemplación de la ciudad desde el norte, coincidiendo con la vista de Toledo de Wyngaerde de $1653^{96}$ (fig. 2) y Vista y Plano de Toledo de El Greco fechada entre 1610 y $1614^{97}$ (fig. 3).

95. Lope de Vega, Vida y muerte del rey Bamba, jornada II, fol. 105v.

96. Sobre la vista de Toledo de Wyngaerde, ver Brown y Kagan, 1984, pp. 49-50 y Kagan, 1986, pp. 132-134. 97. Mann, 1994, p. 107. Fechan la obra en 1608 Gállego, 1972, p. 216; Marías, 2001, p. 7; Troutman, 1967, p. 22. Para la obra de El Greco como vista corográfica o paisaje urbano, ver Marías, 2002, pp. 100 y ss. Sobre Lope de Vega y El Greco se ha ocupado Sánchez Jiménez, 2011, pp. 153-161 y Sánchez Jiménez y Olivares, 2011. 


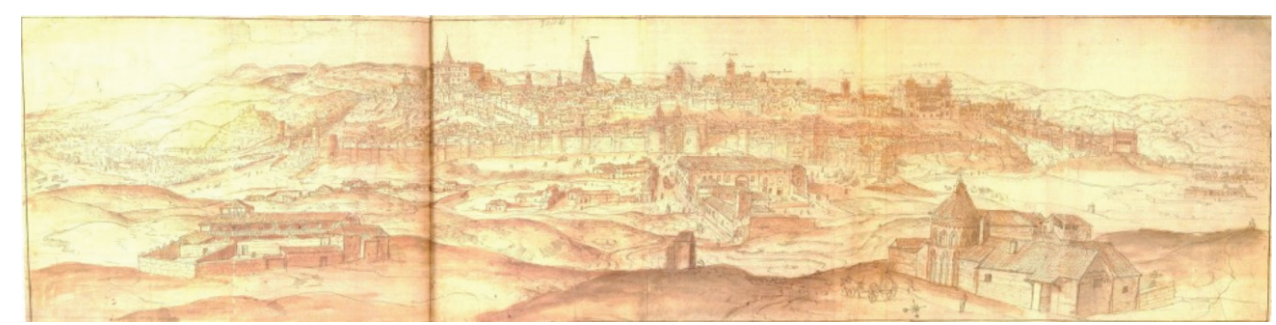

Fig. 2. Vista de Toledo de Anton van den Wyngaerde

(Österreichische Nationalbibliothek, Viena, 1563)

En el caso de la pintura de El Greco, quien representa Toledo como si de una maqueta grisácea se tratase, se ha establecido como posible punto focal un lugar en el cerro de la Horca98 o la cúpula de la iglesia del Hospital de San Juan Bautista de Afuera99. Desde ahí se veía la «Vega famosa»-donde se encontraban los vestigios de la ciudad romana, símbolo de la antigüedad de Toledo ${ }^{100}$ - y la puerta de Bisagra en la Vía Sacra, a la izquierda el puente de la Alcántara -que Lope aquí no menciona-, el Castillo de San Cervantes y los Palacios de Galiana, y a la derecha las Vistillas con la Puerta del Cambrón y el puente de San Martín. Dentro del caserío se podían ver los perfiles del Alcázar y la Catedral, pero lo que desde ese cerro no podía verse, por muy alto que fuera, era la plaza de Zocodover - que Lope introduce en su vista urbana-, símbolo de la ciudad moderna de calles rectas y largas, plazas amplias y regulares y edificios nobles con fachadas regulares en perspectiva. En este sentido, los poderes locales de una Toledo medieval emprendieron, sobre todo a partir de 1580 con la corte ya en Madrid, las remodelaciones de la calle de Chapinerías, la plaza de la Catedral y de Zocodover, el ayuntamiento con un nuevo edificio de Juan de Herrera, la ampliación de la catedral con la sacristía, el hospital de Tavera, la nueva puerta de Bisagra, la reconstrucción de la puerta del Cambrón, etc. ${ }^{101}$ 


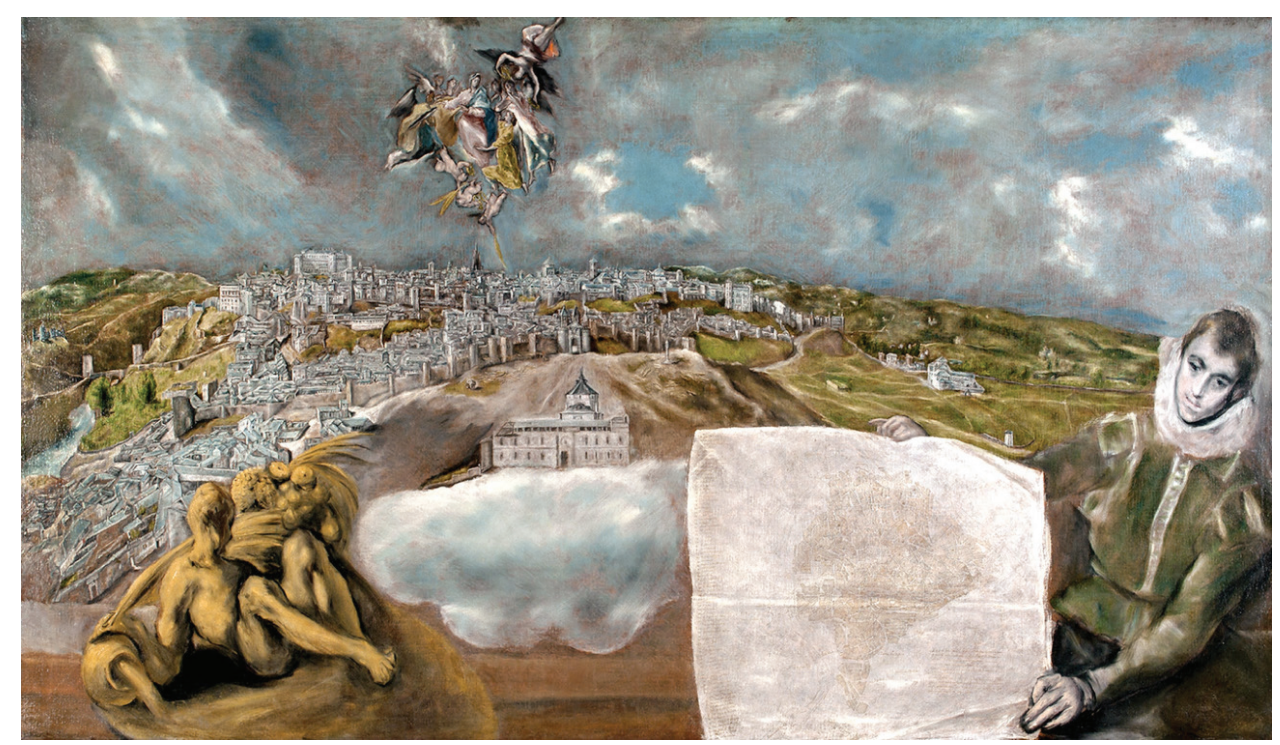

Fig. 3. Vista y plano de Toledo de El Greco (Casa y Museo de El Greco, 1610-1614)

Todo este esfuerzo urbanístico encontró apoyo en los círculos humanistas donde se trataba de recordar la antigüedad de la ciudad a través de topónimos, restos arqueológicos y leyendas tubalistas ${ }^{102}$ que entraron a formar parte del mito simbólico, religioso y, en última instancia, ideológico de la urbe para recuperar la capitalidad perdida ${ }^{103}$. Todas estas ideas y debates aparecían en las historias de ciudades como la de Alcocer, Pisa o incluso la historia de San Ildefonso de Salazar de Mendoza ${ }^{104}$. Muchos de estos debates humanistas fueron introducidos por Lope en sus obras: desde «el muro de Tolemón» ${ }^{105}$ al «aurífero Tajo»106 tan «celebrado por los historiadores y poetas antiguos»107, "corona de dulces aguas» 108 que confiere la forma urbis perfecta ${ }^{109}$, tema tan debatido en el Renacimiento ${ }^{110}$ y

102. Sobre estas cuestiones en las historias de ciudades, ver Quesada, 1992, pp. 59-63.

103. Ver Marías, 1983, pp. 55-57 y 81-82. Para el plan de renovación de la ciudad de Toledo a partir de la década de 1580, ver Díez del Corral Garnica, 1987 y Kagan, 1982, pp. 35-44.

104. Alcocer, Historia o descripción de la cibdad de Toledo (1554); Pisa, Descripción de la Imperial ciudad de Toledo (1605); Salazar de Mendoza, El Glorioso Doctor San llefonso, Arzobispo de Toledo (1618).

105. Lope de Vega, El capellán de la Virgen, acto III, fol. 153r. Fechada entre 1613 y 1616, Morley y Bruerton, 1968, p. 298. Muy probablemente Lope recoge el mito del cónsul romano como primer poblador de Toledo de la Crónica General, una de las fuentes lopescas como ya planteó Menéndez Pelayo, ver Ocampo, Los cinco primeros libros de la Crónica general de España, libro II, cap. II, fol. LXXX.

106. Lope de Vega, El capellán de la Virgen, acto III, fol. 153r.

107. Pisa, Descripción de la Imperial ciudad de Toledo, libro I, cap. VI, fol. 14v. Ver Covarrubias, Tesoro de la lengua castellana o española, fol. 37v.

108. Lope de Vega, El capellán de la Virgen, acto I, fol. 138r.

109. Para la descripción de la isla de Atlántida, ver Platón, Critias, 113a/114c, p. 1195 y 115a/117c, p. 1197. 110. Alberti afirma, en relación a las murallas, que «la ciudad redonda será la más capaz» (Alberti, Los diez libros de arquitectura, libro IV, p. 116.33-34). 
que podemos observar en el grabado de Toledo del libro de Pérez de Mesa (fig. 4) tomado de Pedro de Medina ${ }^{111}$. El río era símbolo y enclave ideal de la ciudad como hemos visto también para el caso de Valencia. Como en un espejo de ciudades ${ }^{112}$, de manera análoga al espejo de príncipes Toledo «mira su antigua cabeza», imagen idealizada en «los espejos del Tajo» ${ }^{113}$. Junto con el río, el asentamiento natural de Toledo como "nueva Roma" sobre montes ${ }^{114}$ y rodeado de muros y agua se convirtió en icono de la propia ciudad, como demuestran las primeras descripciones de la urbe en las que los cronistas destacan principalmente el sitio en altura ${ }^{115}$. Asociado indisolublemente con el río, y convertido también en metonimia de la ciudad, son las «ruedas sonaras» ${ }^{116}$ del artificio de Juanelo Turriano ${ }^{117}$ que introduce también Lope en su iconografía laudatoria.

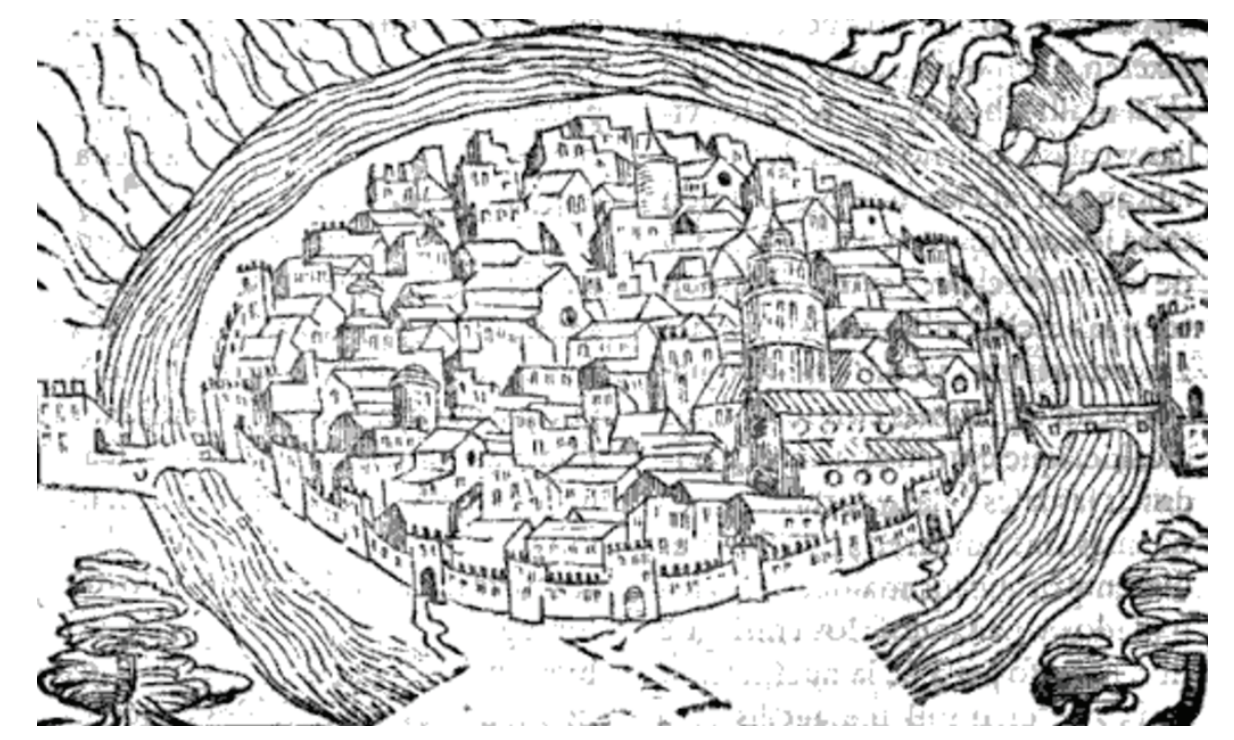

Fig. 4. Vista de Toledo (Pérez de Mesa, Primera y Segunda parte de las grandezas y cosas memorables de España, libro II, cap. LXXIII, fol. 198r)

111. Medina, Libro de las grandezas y cosas memorables de España, fol. 85. Para la iconografía de la muralla como vehículo de valores simbólicos, ver De Seta, 1991, p. 24

112. Tomo el concepto de Olmedo, 2008, cit. en Peña Díaz, 2015.

113. Lope de Vega, Virtud, pobreza y mujer, acto I, escena IV.

114. Sobre el recurso de los siete montes dentro de esa imagen simbólica de Toledo como nueva Roma, ver Martín Gamero, 1862, p. 632; Díez del Corral Garnica, 1987, p. 219; Martínez Gil, 2007.

115. Cfr. Pérez de Mesa, 1595, cap. LXXIII, fol. 198r. Lo toma a su vez de Medina, Libro de las grandezas y cosas memorables de España, fol. 85. Pisa, Descripción de la Imperial ciudad de Toledo, cap. I, fol. 14v-15r. 116. Lope de Vega, El capellán de la Virgen, acto I, fol. 138r.

117. Para una descripción del ingenio hidráulico, ver De la Escosura y Morrogh, 1888. Remitimos también a Porres Martín-Cleto, 1987; Bernabé Merino, 1994; Moreno Santiago, 2017. Para una reconstrucción del funcionamiento, ver Jufre Garcia, 2008. El ingenio que subía el agua al Alcázar debía suscitar gran expectación, pues eran muchos los que iban a la ciudad a ver esa máquina maravillosa. Metonimia de la propia ciudad y argumento en defensa de la capitalidad, se convirtió en símbolo de supremacía técnica de la Monarquía española, Zanetti, 2016, pp. 167-168. 
No cabe duda de que la imagen de la ciudad -en este caso de Valencia y Toledo- en Lope de Vega recibe las influencias o comparte las mismas ideas que se estaban forjando en los círculos humanistas y que aparecen en las descripciones corográficas de estas ciudades. Pero, ¿pudieron de alguna manera influir las vistas de Wyngaerde o de El Greco en las descripciones lopescas de las ciudades? Ya hemos señalado que el poeta pudo ver las vistas de Valencia y de Toledo de Wyngaerde en el Salón Grande del Alcázar. Pero como hemos mencionado, Lope adopta un punto de vista focal más alto, dado que introduce en la vista de Valencia el Hospital General -apenas imperceptible en la vista de Wyngaerde-. También la mención de la plaza de Zocodover en la vista urbana lopesca de Toledo requiere un ángulo de visión más próximo a los $90^{\circ}$ como sería el plano de Valencia de Manceli o el Plano de El Greco, pero ambas obras son posteriores a la comedia de Lope (fechada en 1597 o 1598118). Bien es cierto que algunos investigadores han descartado que haya sido El Greco, o su hijo, el autor del plano de Toledo, atribuyendo al taller de El Greco la simple copia en el cuadro de un plano de la urbe que ya existía y que Francisco Vázquez en 1975 ya había señalado como posible autor a Alonso de Santa Cruz ${ }^{119}$. Si a las fechas nos atenemos, Lope sí pudo conocer este primer plano ortogonal de la ciudad de Toledo tomado desde el norte, que bien puede coincidir con la descripción y el punto focal del poeta. Sin embargo, teniendo en cuenta la enemistad con Salazar de Mendoza ${ }^{120}$ y suponiendo que el plano estuviera en algún archivo privado de familia'21, es poco probable que lo viera.

Cabe suponer, por tanto, que las vistas urbanas de Lope son producto de la contemplación directa de la ciudad en la que se deleitara como muchos eruditos de la época, adoptando como punto focal algún sitio alto (torre o campanario) dentro del caserío que le permitiera ver todos los hitos mencionados. Subirse a un lugar privilegiado desde el que observar el paisaje, la ciudad o el puerto no era algo específico de la profesión de cartógrafos o artistas. Era una actividad que formaba parte de la experiencia de una visita a un lugar. Dentro de la cultura visual de la época se consideraba un "género señorial» que «implicaba y expresaba poder» 122 en otras partes de Europa, donde bien tiene cabida España. En el caso de Valencia podría haber sido desde el Micalet y en el caso de Toledo desde la catedral -como en la mayoría de los trabajos preparatorios de Santa Cruz- o desde las torres de san Miguel, el Alcázar, Sahélices, san Román o san Nicolás desde las que también

118. Morley y Bruerton, 1968, p. 223.

119. Vázquez Maure, 1982a y 1982b, pp. 211-212. Ver Sanz Crespo, 2016. Sobre las fechas de realización del plano hay varias teorías, ver Porres Martín-Cleto, 1967, p. 180 y Caviró Martínez, 1992.

120. La enemistad tiene origen con la comedia perdida de San Tirso, ver Madroñal Durán, 2012, p. 304 y 2014. Quizá se deba a eso que Lope nunca haya mencionado al Greco. Sobre la Academia de Fuensalida, donde no figura el nombre de Lope, ver Blecua, 1961, pp. 459-462. Sobre las hipótesis de la relación entre Lope y El Greco, ver Kagan, 1982, p. 61; Portús Pérez, 1999, p. 142; Camón Aznar, 1945, p. 234; Madroñal Durán, 2012. En nuestra opinión, Lope nunca mencionó al pintor precisamente por la enemistad con Salazar de Mendoza, y no porque no lo conociera.

121. Véase Sanz Crespo, 2016.

122. Alpers, 1987, pp. 213-214. Esta autora pone algunos ejemplos de personajes que contemplan el territorio desde cierta perspectiva en Holanda. 
trabajó el cartógrafo para hacer sus mediciones para el plano de Toledo ${ }^{123}$. Ejemplo de esa cultura de la observación, tanto desde fuera del área urbana, como desde algún punto elevado en el interior del caserío, nos la ofrece precisamente Felipe de Gauna en su relación de las bodas de Felipe III en Valencia en 1599. Gauna confirma la presencia de Lope acompañando al marqués de Sarria, futuro conde de Lemos, y evidencia un énfasis en el disfrute de la vista marina, así como de la vista de la ciudad de Valencia, por ejemplo, desde la Casa de Armas en las inmediaciones de la Puerta de la Mar124: «es de linda vista el mar, / y tan cerca de sus muros» ${ }^{125}$.

Concluimos afirmando -y admitiendo que el estudio aquí presentado es muy limitado- que estas vistas urbanas de Lope de Vega no se pueden entender sin tener en cuenta, por un lado, la tradición literaria corográfica que en España se desarrolló con anterioridad al nacimiento de la cartografía urbana y que influyó en la manera de ver y representar la ciudad. La aspiración de Lope al título de cronista en varias ocasiones ${ }^{126}$ y sus aportaciones en este campo con la génesis de San Isidro o las Vírgenes de Atocha y la Almudena lo acercan aún más a este género de crónicas. Puede que incluso se ordenara como sacerdote porque era precisamente este colectivo quien recibía los cargos de historiador ${ }^{127}$. Por otro lado, como hemos intentado demostrar, las vistas parecen ser fruto, además, de una observación directa, coincidiendo con el gusto de la época por la contemplación y descripción de las ciudades. Tanto las laudes hispaniae, género que creemos influyó en estas obras de Lope, como la cartografía urbana, resaltaban las mismas excelencias y admiraban la misma fachada de la ciudad, convertida en imagen oficial de la urbe, codificando una geografía humanista que abarcaba la historia, los mitos y las alegorías de la ciudad.

\section{BiBLIOgRAFÍA}

Alberti, León Battista, Los diez libros de arquitectura de León Baptista Alberto. Trad. asistida por el alarife Francisco Lozano, y basada en la versión italiana de Cosimo Bartoli. Aprobación de Juan de Herrera, Madrid, Alonso Gómez, impresor de su Majestad, 1582.

Alcocer, Pedro de, Historia o descripción de la cibdad de Toledo, Toledo, Juan Ferrer, 1554.

Aldana Fernández, Salvador, «La Valencia del humanismo en la obra de Anton van den Wyngaerde», Archivo de Arte Valenciano, 68, 1987, pp. 26-37.

Alpers, Svetlana, El arte de describir. El arte holandés en el siglo XVII, Madrid, Hermann Blume, 1987.

123. Sanz Crespo, 2016.

124. Remitimos al lector a la relación de Gauna citada en Bérchez y Gómez Ferrer, 2006, p. 19.

125. Lope de Vega, El bobo del colegio, acto I, vv. 653-654.

126. Sobre la aspiración de Lope al puesto de cronista, ver Weiner, 1986; Wright, 2001; Sánchez Jiménez, 2007; Ferrer Valls, 2008.

127. Sobre los eclesiásticos y la redacción de historias de ciudades, ver Quesada, 1992, pp. 12 y ss. 
Arellano Ayuso, Ignacio, y Mata, Carlos, Vida y obra de Lope de Vega, Madrid, Homo Legens, 2011.

Bérchez, Joaquín, y Gómez Ferrer, Mercedes, «Mirar y sentir la ciudad. La Valencia al viu en el siglo XVII», en En torno al Barroco. Miradas múltiples, coord. Concepción de la Peña Velasco, Murcia, Universidad de Murcia, 2006, pp. 13-28.

Bernabé Merino, María Luisa, «El problema del agua en Toledo en la Edad Moderna», Docencia e Investigación. Revista de la Escuela Universitaria de Magisterio de Toledo, 4, 1994, pp. 25-40.

Blecua, José Manuel, «La academia poética del Conde de Fuensalida», Nueva Revista de Filología Hispánica, 15.3/4, 1961, pp. 459-462.

Boira Maiques, Josep Vicent, La ciudad de Valencia y su imagen pública, Valencia, Universidad de Valencia, 1992.

Botero, Giovanni, Diez libros de la razón de Estado. Con tres libros de las causas de la grandeza y magnificencia de las ciudades de Juan Botero. Traducido de italiano en castellano, por mandado del rey nuestro señor, por Antonio de Herrera, su criado, Madrid, Luis Sánchez, 1593.

Braun, Georg, y Hogenberg, Frans, Civitates Orbis Terraum, ed. Raleigh Ashlin Skelton, Ámsterdam, Theatrum Orbis Terrarum, 1965.

Brown, Jonathan, y Kagan, Richard L., «La Vista de Toledo», en Jonathan Brown, Visiones del pensamiento. El Greco como intérprete de la historia, la tradición y las ideas, Madrid, Alianza, 1984, pp. 37-55.

Cámara Muñoz, Alicia, «Los guardianes del mar: fortificaciones, torres y atalayas en la costa valenciana (SS. XVI-XVII)», en Jornadas del Bicentenario de Torrevieja, 1803-2003, ed. J. Fernando Vera, Alicante, Universidad de Alicante, 2005, pp. 201-220.

Cámara Muñoz, Alicia, «La ciudad en la literatura del Siglo de Oro», Anales de historia del arte, 1, 2008, pp. 121-134.

Cámara Muñoz, Alicia, «Modelos vs perspectivas en la ingeniería del siglo XVI», Artigrama, 31, 2016, pp. 257-277.

Cámara Muñoz, Alicia, y Gómez López, Consuelo, La imagen de la ciudad en la Edad Moderna, Madrid, Editorial Universitaria Ramón Areces, 2011.

Camón Aznar, José, «Citas de arte en el teatro de Lope de Vega», Revista de Ideas estéticas, 9, 1945, pp. 233-274.

Campo Muñoz, Juan del, Viso del Marqués. Apuntes para una historia y descripción del Palacio de monumentos, Valdepeñas, Hernán, 2004.

Carducho, Vicente, Diálogos de la pintura, Valladolid, Editorial Maxtor, 2011.

Caviró Martínez, Balbina, «La calle real de Toledo y el Ilamado plano del Greco», Beresit. Revista Interdiciplinar científico-humana, 4, 1992, pp. 169-199. 
Checa Cremades, Fernando, Felipe II. Mecenas de las Artes, Madrid, Nerea, 1992.

Checa Cremades, Fernando (dir.), El Real Alcázar de Madrid, Madrid, Nerea, 1994.

Cisneros Álvarez, Pablo, La imagen grabada de la ciudad de Valencia entre 1499 y 1695, tesis de doctorado, dir. Mercedes Gómez-Ferrer Lozano, Valencia, Universidad de Valencia, 2012.

Covarrubias Orozco, Sebastián, Tesoro de la lengua castellana o española. Parte segunda..., Madrid, por Melchor Sánchez, a costa de Gabriel León, 1674.

Davis, Charles, 27 documentos de Lope de Vega Carpio en el Archivo Histórico de Protocolos de Madrid, Madrid, Comunidad de Madrid, 2004.

De Seta, Cesare, «Las murallas, símbolo de la ciudad», en La ciudad y las murallas, coord. Cesare De Seta y Jacques Le Goff, Madrid, Cátedra, 1991, pp. 21-66.

De Seta, Cesare, «L'iconografia urbana in Europa dal XV al XVIII secolo», en Città di Europa. Iconografia e vedutismo dal XV al XIX secolo, ed. Cesare De Seta, Nápoles, Electa, 1996, pp. 11-48.

De Seta, Cesare, «La fortuna del ritratto di prospettiva e l'immagine delle città italiane nel Rinascimento», en A volo d'uccello. Jacopo de Barberi e la rappresentazione di città nell'Europa del Rinascimento, coord. Giandomenico Romanelli et al., Venecia, Arsenale, 1999, pp. 28-38.

De Seta, Cesare, y Le Goff, Jacques (coords.), La ciudad y las murallas, Madrid, Cátedra, 1991.

Devos, Brent W., «Un aspecto de la técnica dramática de Calderón: la geografía y toponimia en El Tuzaní de las Alpujarras», en En torno al teatro del Siglo de Oro. Jornadas XXI-XXIII, coord. Antonio Serrano, Almería, Instituto de Estudios Almerienses, 2007, pp. 83-92.

Díez Borque, José María, «Aproximación semiológica a la "escena" del teatro del Siglo de Oro español», en Semiología del teatro, coord. Luciano García Lorenzo y José María Díez Borque, Barcelona, Grupo Planeta, 1975, pp. 49-92.

Díez Borque, José María, Los espectáculos del teatro y de la fiesta en el Siglo de Oro español, Madrid, Ediciones del Laberinto, 2002.

Díez del Corral Garnica, Rosario, Arquitectura y mecenazgo. La imagen de Toledo en el Renacimiento, Madrid, Alianza Forma, 1987.

Escolano, Gaspar, Década primera de la Historia de la insigne y coronada ciudad y Reino de Valencia, Parte 1, Valencia, Patricio Mey, 1610.

Escosura y Morrogh, Luis de la, El artificio de Juanelo y el puente de Julio César, Madrid, Imprenta de Luis Aguado, 1888.

Esteban Piñeiro, Mariano, «Las academias técnicas en la España del siglo XVI», Quaderns d'història de l'enginyeria, 5, 2002, pp. 10-19. 
Ferrer Valls, Teresa, «Teatro y mecenazgo en el Siglo de Oro: Lope de Vega y el duque de Sessa», en Mecenazgo y Humanidades en tiempos de Lastanosa. Homenaje a Domingo Ynduráin, ed. Aurora Egido, Huesca, Instituto de Estudios Altoaragoneses, 2008, pp. 113-134.

Ferrer Valls, Teresa, «Lope y la creación de héroes contemporáneos: La nueva victoria de don Gonzalo de Córdoba y La nueva victoria del marqués de Santa Cruz», Anuario Lope de Vega. Texto, literatura, cultura, XVIII, 2012, pp. 40-62.

Galera i Monegal, Montserrat, Antoon van den Wijngarde, pintor de ciudades y hechos de armas en la Europa del Quinientos. Cartobibliografía razonada de los dibujos y grabados, y ensayo de reconstrucción documental de la obra pictórica, Barcelona, Institut Cartogràfic de Catalunya, 1998.

Gállego, Julián, «El Greco», en Historia del Arte, ed. J. Pijuán, Barcelona, Salvat, 1972, VI, pp. 191-221.

García Barreno, Pedro, «La Academia de Matemáticas de Madrid de Felipe Il», en La Real Academia de Ciencias 1582-1995, Madrid, Real Academia de Ciencias Exactas, Físicas y Naturales, 1995.

García Barreno, Pedro, «Avatares de la Academia de Matemáticas de Felipe Il», en Institución de la Academia Real Matemática, ed. Juan Antonio Yeves Andrés, Madrid, Instituto de Estudios Madrileños, 2006, pp. 135-195.

García Mercadal, José, Viajes de extranjeros por España y Portugal, vol. I, Salamanca, Junta de Castilla y León, 1999.

Gómez-Ferrer Lozano, Mercedes, Arquitectura y arquitectos en la Valencia del siglo XVI: el Hospital General y sus artífices, Valencia, Universidad de Valencia, 1995.

Gómez López, Consuelo, «La imagen de la ciudad como estrategia de poder. Pintores y dibujantes en las cortes europeas», en Representar la ciudad en la Edad Moderna. 1565, Wyngaerde en Alcalá, coord. Antonio Fernández Fernández et al., Madrid, UNED, 2016.

Haverkamp-Begemann, Egbert, «Las vistas de España de Anton Van den Wyngaerde», en Ciudades del Siglo de Oro: las vistas españolas de Anton van den Wyngaerde, coord. Richard L. Kagan, Madrid, El Viso, 1986, pp. 54-67.

IBSO. Bases de datos sobre inventarios y bibliotecas del Siglo de Oro, <http://www. bidiso.es/IBSO/BusquedaGeneral.do>.

Jufre Garcia, Xavier, El artificio de Juanelo Turriano para elevar agua al Alcázar de Toledo: modelo con escaleras de Valturio, Barcelona, Editorial Milenio, 2008.

Kagan, Richard L., «La Toledo del Greco», en El Greco de Toledo, coord. Jonathan Brown, Madrid, Ministerio de Cultura / Banco Urquijo, 1982, pp. 35-73.

Kagan, Richard L. (dir.), Ciudades del Siglo de Oro: las vistas españolas de Anton van den Wyngaerde, Madrid, El Viso, 1986. 
Kagan, Richard L., «La corografía en la Castilla moderna: género, historia, nación», en Studia Aurea. Actas del III Congreso de la AISO, Toulouse-Pamplona, 1993, coord. Ignacio Arellano Ayuso et al., Pamplona / Toulouse, GRISO / LEMSO, 1996, vol. 1, pp. 79-91.

Kagan, Richard L., «Urbs and Civitas in Sixteenth- and Seventeenth-Century Spain», en Envisioning the City: Six Studies in Urban Cartography, coord. David Buisseret, Chicago, Universidad de Chicago, 1998a, pp. 75-108.

Kagan, Richard L., Imágenes urbanas del mundo hispánico: 1493-1780, Madrid, El Viso, 1998b.

Kagan, Richard L., «Felipe II y el arte de la representación de paisajes urbanos», Anuaria IEHS: Instituto de Estudios histórico sociales, 24, 2009, pp. 95-110.

Kircher, Athanasius, Ars Magna, Lucis et Umbrae. Liber decimus: reproducción facsimilar da edición de 1671 con estudios introductorios e versións ó galego e castelán, Santiago de Compostela, Universidad de Santiago de Compostela, 2000.

López Terrada, María Luz, El Hospital General de Valencia en el siglo XVI (15131600), tesis doctoral, Valencia, Universidad de Valencia, 1986.

López Torrijos, Rosa, Entre España y Génova. El Palacio de don Álvaro de Bazán en el Viso, Madrid, Ministerio de Defensa, 2009.

López Torrijos, Rosa, «Las galerías de ciudades en el siglo XVI», en Representar la ciudad en la Edad Moderna. 1565, Wyngaerde en Alcalá, coord. Antonio Fernández Fernández et al., Madrid, UNED, 2016.

Madroñal Durán, Abraham, «Entre Cervantes y Lope: Toledo, hacia 1604», eHumanista/Cervantes, 1, 2012, pp. 300-332.

Madroñal Durán, Abraham, «San Tirso de Toledo, tragedia perdida de Lope de Vega», Hipogrifo. Revista de Literatura y Cultura del Siglo de Oro, 2.1, 2014, pp. 23-54.

Mann, Richard G., El Greco y sus patronos. Tres grandes proyectos, Madrid, Akal, 1994.

Maravall, José Antonio, La cultura del Barroco, Barcelona, Ariel, 1983.

Marías, Fernando, La arquitectura del Renacimiento en Toledo (1541-1637), Vol. 2, Editorial CSIC-CSIC Press, 1983.

Marías, Fernando, «Tipologia delle immagini delle città spagnole», en Città d'Europa. Iconografia e vedutismo dal XV al XIX secolo, ed. Cesare de Seta, Nápoles, Electa, 1996, pp. 101-116.

Marías, Fernando, «La arquitectura de la ciudad de Valencia en la encrucijada del siglo XV: Lo moderno, lo antiguo y lo romano», Anuario del Departamento de Historia y Teoría del Arte, 12, 2000, pp. 25-38.

Marías, Fernando, El Greco in Toledo, Londres, Scala, 2001. 
Marías, Fernando, «lmágenes de ciudades españolas: de las convenciones cartográficas a la corografía urbana» en El Atlas del Rey Planeta. La «Descripción de España y las costas y reinos de sus puertos» de Pedro Texeira (1634), ed. Felipe Pereda y Fernando Marías, Nerea, 2002, pp. 99-116.

Martín Gamero, Antonio, Historia de la ciudad de Toledo: sus claros varones y monumentos, Toledo, Imprenta de Severiano López Fando, 1862.

Martínez Gil, Fernando, La invención de Toledo: imágenes históricas de una identidad urbana, Toledo, Almud / Ediciones de Castilla-La Mancha, 2007.

Medina, Pedro de, Libro de las grandezas y cosas memorables de España, Sevilla, en casa de Robertis, 1549.

Moreno Santiago, Ángel, «Maqueta del Artificio de Juanelo Turriano (Toledo)», en Maquetas y modelos históricos: ingeniería y construcción, coord. Pedro Navascués Palacio y Bernardo Revuelta Pol, Madrid, Fundación Juanelo Turriano, 2017, pp. 228-233.

Morley, S. Griswold, y Bruerton, Courtney, Cronología de las comedias de Lope de Vega, Madrid, Gredos, 1968.

Morley, S. Griswold, y Tyler, Richard W., Los nombres de personajes en las comedias de Lope de Vega, Madrid, Castalia, vols. 2, 1961.

Nuti, Lucia, Ritratti di città. Visione e memoria tra Medioevo e Settecento, Venecia, Marsili, 1996.

Nuti, Lucia, «La rappresentazione della città: ricerche, soluzioni, prototipi», en II Rinascimento italiano e l'Europa, vol. VI, Luoghi, spazi, architetture, coord. Donatella Calabi y Elena Svalduz, Treviso Costabissara (Vicenza), Angelo Colla, 2010, pp. 3-16.

Nuti, Lucia, «El nacimiento de un nuevo género de representación el retrato de la ciudad», en Historia de la cartografía urbana en España: modelos y realizaciones, coord. Luis Urteaga y Francesc Nadal Piqué, Madrid, Centro Nacional de Información Geográfica, 2017, pp. 33-45.

Ocampo, Florián de, Los cinco primeros libros de la Crónica general de España, Medina del Campo, Guillermo de Millis, 1553.

Oleza, Joan, «Lugares intangibles: el espacio barroco en la comedia nueva de Lope», en La representación del espacio en la literatura español del Siglo de Oro, ed. Eberhard Geisler, Barcelona, Anthropos, 2013, pp. 206-231.

Olmedo, Fernando, «Imágenes del Guadalquivir en la estampa (siglos XV-XVIII)», en El río Guadalquivir, ed. Javier Rubiales, Sevilla, Consejería de Obras Públicas y Transportes, 2008, pp. 525-533.

Panofsky, Erwin, La perspectiva como forma simbólica, Barcelona, Tusquets, 1973.

Pedersen, Olaf, Early Physics and Astronomy: A Historical Introduction, Cambridge, Universidad de Cambridge, 1993. 
Peña Díaz, Manuel, «El Guadalquivir: sueños y representaciones en el Siglo de Oro», e-Spania, 21, 2015, s.p.

Pereda, Felipe, «Un atlas de costas y ciudades iluminado para Felipe IV», en El Atlas del Rey Planeta. La «Descripción de España y las costas y reinos de sus puertos» de Pedro Texeira (1634), ed. Felipe Pereda y Fernando Marías, Madrid, Nerea, 2002, pp. 29-48.

Pérez de Mesa, Diego, Primera y Segunda parte de las grandezas y cosas memorables de España, compuesto primeramente por el maestro Pedro de Medina..., Alcalá de Henares, Juan Gracián, 1595.

Piqueras Flores, Manuel, y Santos de la Morena, Blanca, «"Parténope santa": Nápoles en el teatro de Lope de Vega, un acercamiento por géneros», Anuario Lope de Vega. Texto, literatura, cultura, XXV, 2019, pp. 103-121.

Pisa, Francisco de, Descripción de la Imperial ciudad de Toledo, y historia de sus antigüedades, y grandeza, y cosas memorables, los reyes que la han señoreado, o gobernado, y sus arzobispos más celebrados. Primera parte con la historia de Santa Leocadia, Toledo, 1605.

Platón, Critias, en Obras completas, trad. María Araujo et al., Madrid, Aguilar, 1981.

Porres Martín-Cleto, Julio, «Plano de Toledo» de Doménico Theotocópuli El Greco, Toledo, Instituto de Investigaciones y Estudios Toledanos / Diputación de Toledo, 1967.

Porres Martín-Cleto, Julio, El Artificio de Juanelo, Toledo, Diputación Provincial de Toledo, 1987.

Portús Pérez, Javier, Pintura y pensamiento en la España de Lope de Vega, Guipúzcoa, Nerea, 1999.

Presotto, Marco, Le commedie autografe di Lope de Vega. Catalogo e studio, Kassel, Edition Reichenberger, 2000.

Quesada, Santiago, La idea de ciudad en la cultura hispana de la Edad Moderna, Barcelona, Universidad de Barcelona, 1992.

Ramírez Aledón, Germán, «El plano de Valencia de Antonio Manceli (1608): noticias, vicisitudes y aclaraciones de un documento excepcional, pero no único», en AA. VV., Pasiones bibliográficas II, Valencia, Societat Bibliogràfica Valenciana Jerònima Galés, 2017, pp. 165-176.

Riello, José, La biblioteca del Greco, Madrid, Museo Nacional del Prado, 2014.

Rodrigo Pertegás, José, «Hospitales de Valencia en el siglo XV: su administración, régimen interior y condiciones higiénicas», Boletín de la Real Academia de Historia, 1927, pp. 561-609.

Romero Carrión, Manuel, «Toledo en el paisaje del Greco», Anales toledanos, 7, 1973, pp. 157-174. 
Romo Santos, María Concepción, Felipe II protector de las Matemáticas, Sevilla, Punto Rojo, 2016.

Roselló, Vicenç (dir.), Les viste valencianes d'Anthonie van den Wjingaerde (1563), Valencia, Conselleria de Cultura, 1990.

Salazar de Mendoza, Pedro, El Glorioso Doctor San Ilefonso, Arzobispo de Toledo, Primado de las Españas, Toledo, Diego Rodríguez, 1618.

Sánchez Cantón, Francisco Javier, «La librería de Velázquez», en Homenaje a Menéndez Pidal. Miscelánea de estudios lingüísticos, literarios e históricos, Madrid, Hernando, 1925, vol. 3, pp. 379-406.

Sánchez Jiménez, Antonio, «Lope, historiador de Indias: las fuentes documentales de La Dragontea (1598)», Anuario Lope de Vega. Texto, literatura, cultura, XIII, 2007, pp. 133-152.

Sánchez Jiménez, Antonio, «La edición de textos en 2009: el Isidro (1599), de Lope de Vega, y la lista de "Los libros y autores que se citan para la exornación de esta historia"», Boletín Hispánico Helvético, 15, 2010, pp. 103-139.

Sánchez Jiménez, Antonio, El pincel y el Fénix: pintura y literatura en la obra de Lope de Vega y Carpio, Madrid, Iberoamericana, 2011.

Sánchez Jiménez, Antonio, «Memoria tradicional e historia en dos corografías piadosas de Lope de Vega: las invenciones de Nuestra Señora de Atocha (Isidro, cantos VIII y IX) y La Virgen de la Almudena», Anuario Lope de Vega. Texto, literatura, cultura, XVIII, 2012, pp. 175-209.

Sánchez Jiménez, Antonio, y Olivares, Julián, «Lope de Vega y El Greco: Ut pictura poesis en el Toledo del siglo XVII», Bulletin of Hispanic studies, 88.1, 2011, pp. 21-42.

Santiago Páez, Elena, «Las bibliotecas del Alcázar en tiempo de los Austrias», en El Real Alcázar de Madrid, dir. Fernando Checa Cremades, Madrid, Nerea, 1994, pp. 318-343.

Sanz Crespo, Antonio, «El empleo de métodos topográficos en las primeras representaciones urbanas. El Greco y el enigma del mapa de Toledo», CT: Catastro, 87, 2016, pp. 57-86.

Skelton, Raleigh Ashlin, «Introducción», en Georg Braun y Frans Hogenberg, Civitates Orbis Terrarum, Ámsterdam, Theatrum Orbis Terrarum, 1965.

Soraluce Blond, José Ramón, «Ciencia y arquitectura en el ocaso del Renacimiento. Notas para la historia de la Real Academia de Matemáticas de Madrid», Academia, 65, 1987, pp. 67-107.

Tropé, Hélène, Locura y sociedad en la Valencia de los siglos XV la XVII: los locos del Hospital de los Inocentes (1409-1512) y del Hospital General (1512-1699), Valencia, Diputación de Valencia / Centre d'Estudis d'História Local, 1994.

Troutman, Philip, El Greco, Londres, Paul Hamlyn, 1967. 
Valdés, Ramón, «Claves e hipótesis para la interpretación de la octava maravilla: fuentes, motivos simbólicos y trasfondo histórico», Anuario de Lope de Vega, VII, 2001, pp. 165-189.

Vázquez Maure, Francisco, «El plano de Toledo del Greco y su posible origen», Boletín de la Real Sociedad Geográfica, 98, 1982a, pp. 151-155.

Vázquez Maure, Francisco, «Cartografía de la península: siglos XVI a XVIII», Boletín de la Real Sociedad Geográfica, 98, 1982b, pp. 215-235.

Vega, Lope de, De cuando acá nos vino, edición digital a partir de Obras de Lope de Vega, XI, ed. Emilio Cotarelo y Mori, Madrid, RAE, 1929, pp. 670-711.

Vega, Lope de, El abanillo, edición digital a partir de Obras de Lope de Vega, III, ed. Emilio Cotarelo y Mori, Madrid, RAE, 1917, pp. 1-32.

Vega, Lope de, El alcaide de Madrid, edición digital a partir de Obras de Lope de Vega, I, ed. Emilio Cotarelo y Mori, Madrid, RAE, 1916, pp. 547-584.

Vega, Lope de, El amante agradecido, edición digital a partir de Obras de Lope de Vega, III, ed. Emilio Cotarelo y Mori, Madrid, RAE, 1917, pp. 100-140.

Vega, Lope de, El Arenal de Sevilla, edición digital a partir de Oncena parte de las comedias de Lope de Vega Carpio, Barcelona, Sebastián de Cormellas, 1618.

Vega, Lope de, El bobo del colegio, edición de Purificació Mascarell para el proyecto ARTELOPE, Valencia, Biblioteca Digital ARTELOPE, 2015.

Vega, Lope de, El Capellán de la Virgen, reproducción digital a partir de Decimaoctava parte de las comedias de Lope de Vega Carpio..., Madrid, Juan González, 1623, fols. 132v-157.

Vega, Lope de, El casamiento en la muerte, edición digital a partir de Obras completas de Lope de Vega, IV, Madrid, Turner Libros (Biblioteca Castro), 1993, pp. 325-409.

Vega, Lope de, El castigo del discreto, edición digital a partir de Obras de Lope de Vega, IV, ed. Emilio Cotarelo y Mori, Madrid, RAE, 1917, pp. 183-222.

Vega, Lope de, El desconfiado, edición digital a partir de Obras de Lope de Vega, III, ed. Emilio Cotarelo y Mori, Madrid, RAE, 1917, pp. 477-506.

Vega, Lope de, El Grao de Valencia, edición digital a partir de Obras de Lope de Vega, I, ed. Emilio Cotarelo y Mori, Madrid, RAE, 1916.

Vega, Lope de, El peregrino en su patria, Barcelona, Sebastián de Cormellas, 1605.

Vega, Lope de, La burgalesa de Lerma, edición digital a partir de Obras de Lope de Vega, IV, ed. Emilio Cotarelo y Mori, Madrid, RAE, 1917, pp. 30-73.

Vega, Lope de, La nueva victoria del Marqués de Santacruz, reproducción digital a partir de Parte veintecinco, perfeta y verdadera, de las comedias del Fénix de España frey Lope Félix de Vega Carpio..., Zaragoza, viuda de Pedro Vergés, a costa de Roberto Devport, 1647, fols. 183-230. 
Vega, Lope de, La octava maravilla, edición digital a partir de Obras de Lope de Vega, VIII, ed. Emilio Cotarelo y Mori, Madrid, RAE, 1930, pp. 246-285.

Vega, Lope de, La prisión sin culpa, en Séptima parte de sus comedias. Con loas, entremeses y bailes, Madrid, Alonso Martín, 1617.

Vega, Lope de, La Vega del Parnaso, ed. Felipe B. Pedraza Jiménez y Pedro Conde Parrado, tomo 3, Cuenca, Ediciones de la Universidad de Castilla-La Mancha, 2015.

Vega, Lope de, Los locos de Valencia, edición digital a partir de Los locos de Valencia, ed. Hélène Tropé, Madrid, Castalia, 2003.

Vega, Lope de, Los ramilletes de Madrid, en Doce comedias de Lope de Vega Carpio ... sacadas de sus originales... Oncena parte, Barcelona, Sebastián de CormeIlas, 1618, fols. 51r-72v.

Vega, Lope de, Porfiando vence amor, en La Vega del Parnaso, Madrid, en la Imprenta del Reino, 1637.

Vega, Lope de, Soliloquios amorosos de un alma a Dios, Madrid, en la imprenta de Música, Juan de San Miguel, 1756.

Vega, Lope de, Vida y muerte del Rey Bamba, reproducción digital a partir de la Primera parte de las comedias del famoso poeta Lope de Vega Carpio..., Zaragoza, Angelo Tauanno, 1604, fols. 91r-119v.

Vega, Lope de, Virtud, pobreza y mujer, reproducción digital a partir de Parte veinte de las comedias de Lope de Vega Carpio..., Madrid, viuda de Alonso Martín, a costa de Alonso Pérez, 1625.

Vilar Devis, Mercedes, El hospital General de Valencia en el siglo XVII, tesis doctoral, Valencia, Universidad de Valencia, 1990.

Vitruvio Polión, Marco, De Architectura, dividido en diez libros, traducidos de latín en castellano por Miguel de Urrea..., Alcalá de Henares, Juan Gracián, 1582.

Vitse, Marc, «Sobre los espacios en La dama duende: el cuarto de don Manuel», Revista de filología hispánica, 12.2, 1996, pp. 337-356.

Weiner, Jack, «Lope de Vega, un puesto de cronista y La hermosa Ester (16101621)», en Actas del VIII Congreso de la Asociación Internacional de Hispanistas, 22-27 de agosto 1983, ed. A. David Kossoff, José Amor Vázquez, Ruth H. Kossoff y Goffrey Ribbans, Madrid, Istmo, 1986, vol. 2, pp. 727-734.

Wright, Elizabeth R, Pilgrimage to Patronage: Lope de Vega and the Court of Philip III, 1598-1621, Lewisburg, Bucknell University Press, 2001

Zamora Vicente, Alonso, Lope de Vega. Su vida y su obra, Madrid, Gredos, 1961.

Zanetti, Cristiano, Janello Torriani, genio del Rinascimento, Catálogo de la exposición en Cremona, Museo del Violino, 2016. 
Zaragoza Rubira, Juan Ramón, «El hospital de Inocentes de Valencia en la obra de Lope», Medicina Española, 51, 1964a, pp. 413-424.

Zaragoza Rubira, Juan Ramón, «Lope de Vega y los locos de Valencia», Medicamenta, 41, 1964b, pp. 351-356. 